\title{
Lattice-solvent effects in the Spin-crossover of an Fe(II)-based material. The key role of intermolecular interactions between solvent molecules
}

\author{
Maria Fumanal, ${ }^{* 1}$ Fernando Jimenez, ${ }^{2}$ J. Ribas-Arino ${ }^{2}$ and Sergi Vela ${ }^{*}, 1$ \\ ${ }^{1}$ Laboratoire de Chimie Quantique, Institut de Chimie UMR 7177 CNRS-Université de \\ Strasbourg, 1 Rue Blaise Pascal BP 296/R8, F-67007 Strasbourg (France) \\ ${ }^{2}$ Departament de Química Física and IQTCUB, Facultat de Química, Universitat de Barcelona, \\ Av. Diagonal 645, 08028-Barcelona (Spain) \\ *E-mail: fumanal@unistra.fr.*E-mail: velallausi@unistra.fr.
}

\begin{abstract}
The spin transition of Fe(II) complexes is the subject of intensive synthetic and computational efforts. In this manuscript, we analyze the spin crossover (SCO) of $\left[\mathrm{Fe}(E \text {-dpsp })_{2}\right]^{2+}(\mathbf{1})$, which features a spin transition depending on the cocrystallizing solvent molecules. Whereas the use of acetone results in a hysteretic spin transition at $\sim 170 \mathrm{~K}$, the use of propylene carbonate (PC) results in a permanent diamagnetic signal up to $300 \mathrm{~K}$. By means of DFT+U+D2 calculations in the solid state of the material, we unravel the reasons for such different behavior. Our results allow us to ascribe the relatively low transition temperature of $\mathbf{1}\left(\mathrm{BF}_{4}\right)_{2}$. acetone to the distorted arrangement of the SCO molecules in the low-spin state of the material. In turn, intermolecular interactions play the primary role in the case of $1\left(\mathrm{BF}_{4}\right)_{2} \cdot 2 \mathrm{PC}$. In particular, we found that solvent-solvent interactions actively promote the stability of the low-spin state due to the formation of PC dimers. These dimers would appear at larger distances in the high-spin phase, with the subsequent loss of phase stability. This is yet another proof of how subtle is the spin transition phenomenon in Fe(II)-based architectures.
\end{abstract}




\section{INTRODUCTION}

Spin crossover (SCO) compounds are among the most promising molecular materials to be used as molecular switches in technology devices. ${ }^{(1-4)}$ The possible coexistence of their magnetically silent and magnetically active states makes them extremely interesting in that regard. In the case of octahedral Fe(II)-based complexes, the spin transition occurs between a diamagnetic low-spin state (LS, $S=0$ ) and a paramagnetic high-spin state (HS, $S=2$ ). In the former state, six electrons are distributed in the three nonbonding " $3 \mathrm{~d}$ " orbitals of the metal ion $\left(\mathrm{t}_{2 \mathrm{~g}}\right)$. This state is stabilized by the larger enthalpy $(H)$ that results from the effective coordination of the metal and the ligands. In turn, the HS state exists due to the entropy-favorable unpairing of four of those six delectrons, yielding the quintuplet state. ${ }^{(5-7)}$ As a result, the two antibonding $\mathrm{e}_{\mathrm{g}}$ orbitals become populated, which implies the weakening of the metal-ligand coordination, manifested itself in an enlargement of the Fe-ligand distance (also exploited in applications ${ }^{(8)}$ ). This is usually associated with an enthalpy loss and with a notable increase in vibrational and electronic entropy $(S)$. This picture, based on the changes in the $\mathrm{Fe}$ atom and the coordination sphere, contains the key aspects occurring at the molecular level, and it is useful to understand the basics of the SCO transition. In some cases, it is even possible to connect the $t_{2 g}$ - $e_{g}$ energy difference, indicative of the strength of the ligand field, with the transition temperature of the material $\left(T_{1 / 2}\right){ }^{(9)}$ However, most often this elegant and rather simplified picture is not sufficient. Still at the molecular level, intra- and interligand interactions (i.e., intramolecular) can play a key role in modulating the stability of the LS and HS states. ${ }^{(10,11)}$ In the solid state, the subtle energy balance between HS and LS can be further affected by intermolecular interactions, whose contribution to $\Delta H$ can be of the same order as $\Delta H$ itself. $^{(12)}$ It becomes evident that the strength of the ligand-field is, indeed, just one contributor to the stability of the LS and HS phases. Therefore, a thorough knowledge of thermal SCO transitions requires an exhaustive evaluation of all the elements that we have previously mentioned.

Pseudo-octahedral Fe(II)-based compounds coordinated to ligands through $\mathrm{N}$ atoms are the largest family of SCO systems. The reason is that in these architectures the strength of the ligand field is the most adequate to generate both HS and LS states depending on the external conditions (pressure, temperature) and environment (solvent, crystal packing). Among them, the family of bis(pyrazol-X-yl)pyridine ligands (X-bpp, $\mathrm{X}=$ $1,3)^{(13,14)}$ is particularly interesting, because it has furnished spectacular examples of systems for which the subtle effects that arise from the crystal packing are a key factor in defining its SCO behavior. In previous studies by some of us, we analyzed the counterion-dependent kinetic trapping in $\left[\mathrm{Fe}^{\mathrm{II}}\left(1-\mathrm{bpp}_{2}\right)\right]^{2+}$ species. ${ }^{(15)}$ Following our line of research, in this work we focused our attention on the role of the crystal-solvent molecules (i.e., solvent molecules that remain in the lattice after crystallization). These species can be crucial in defining the magnetic behavior of SCO materials. For instance, different cocrystallizing solvent molecules can change the transition temperature 
$\left(T_{1 / 2}\right)^{(16-19)}$ or the degree of cooperativity (including the opening of a hysteresis loop) of an SCO material.(20) Even more interesting are the single-crystal-to-single-crystal transformations of molecular systems resulting from exchange of lattice solvent molecules. ${ }^{(21-25)}$ Remarkably, this type of transformation could be recently followed in real-time, revealing the transformation mechanism at the molecular scale. ${ }^{(26)}$ All these elements highlight that the thermal SCO can be tunable upon adsorption-desorption of the crystal-solvent molecules or, in other words, it highlights the potential of SCO materials to be employed as chemosensors. ${ }^{(27)}$ In particular, SCO-based metal-organic frameworks (MOFs) are highly promising because of their permanent porosity. ${ }^{(28-36)}$

In recent years, the computational analysis of the solid state of SCO systems has become accessible thanks to the development and proper benchmark of the DFT+U+D2 scheme. $^{(10,12,15,37-41)}$ The DFT $+\mathrm{U}$ methodology is extensively used in solid-state physics to study strongly correlated systems (involving $\mathrm{d}$ or $\mathrm{f}$ localized electrons) because of its simplicity and low computational cost. ${ }^{(42)}$ A variety of phenomena such as electrical conductivity, ${ }^{(43)}$ adsorption on surfaces, ${ }^{(44,45)}$ or chemical reactivity ${ }^{(46)}$ are successfully studied by means of this approach. In addition, the pairwise Grimme D2 correction $^{(41,47)}$ provides a good description of the long-range interactions necessary to treat dispersion forces between molecular contacts, otherwise energetically underestimated. Thus, the DFT+U+D2 computational framework allows for the accurate evaluation of spin states, and of intra- and intermolecular interactions, thus yielding enthalpy values that are directly comparable to experiment. As a result, the role of the counterions could be analyzed in some computational works. ${ }^{(15,38)}$ However, the influence of the lattice-solvent molecules has still not been evaluated (to our knowledge). For this reason, we felt that it was interesting to investigate this particular point in the spin transition of a synthetic SCO material.

With this aim in mind, in this work we studied another member of the $\left[\mathrm{Fe}^{\mathrm{II}}\left(1-\mathrm{bpp}_{2}\right)\right]^{2+}$ family, namely, the $\mathrm{Fe}(E \text {-dpsp })_{2}\left(\mathrm{BF}_{4}\right)_{2} \cdot \mathrm{X} \quad(\mathrm{dpsp}=2,6$-bis(1H-pyrazol-1-yl)-4styrylpyridine) complex (see Figure 1a), where $X$ corresponds to different crystal solvents. Hereafter, $\left[\mathrm{Fe}(E-\mathrm{dpsp})_{2}\right]^{2+}$ is referred to as $\mathbf{1}$. The $E$ conformer of this compound has the ability to encapsulate crystal-solvent molecules, in contrast to the $Z$ dpsp form, which crystallizes as a solvent-free material. ${ }^{(48)}$ Experimentally, Hasegawa et al. found that $\mathbf{1}\left(\mathrm{BF}_{4}\right)_{2}$ is prone to give rise to different polymorphs depending on the solvent used. ${ }^{(49)}$ For instance, $\mathbf{1}\left(\mathrm{BF}_{4}\right)_{2} \cdot 4 \mathrm{MeNO}_{2}$ remains in the HS in all range of temperatures, as well as $\mathbf{1}\left(\mathrm{BF}_{4}\right)_{2} \cdot \mathrm{H}_{2} \mathrm{O} \cdot 3 \mathrm{MeCN}$ crystal, which exhibited HS state up to 5 $\mathrm{K}$. In turn, $1\left(\mathrm{BF}_{4}\right)_{2} \cdot 0.5 \mathrm{Et}_{2} \mathrm{O}$ and $\mathbf{1}\left(\mathrm{BF}_{4}\right)_{2} \cdot 2 \mathrm{PC}(\mathrm{PC}=$ propylene carbonate $)$ show LS structural characteristics and diamagnetic signal down to $300 \mathrm{~K}$. Much more interesting is the behavior of $\mathbf{1}\left(\mathrm{BF}_{4}\right)_{2}$ acetone, which undergoes a cooperative thermal spin crossover, at a relatively low temperature, and with a $15 \mathrm{~K}$ hysteresis loop $\left(T_{1 / 2 \uparrow}=179\right.$ $\mathrm{K}, T_{1 / 2 \downarrow}=164 \mathrm{~K}$, see Figure $1 \mathrm{~b}$ ). The different thermal SCO behavior of these $\mathbf{1}\left(\mathrm{BF}_{4}\right)_{2} \cdot \mathrm{X}$ materials, which are constituted by the same Fe(II) unit and counterion, represents a good opportunity to investigate, from first principles, the structural and electronic solid-state effects of the crystal-solvent molecules and their role in giving rise to different solvatomorphs. In particular, $\mathbf{1}\left(\mathrm{BF}_{4}\right)_{2} \cdot$ acetone and $\mathbf{1}\left(\mathrm{BF}_{4}\right)_{2} \cdot 2 \mathrm{PC}$ materials are 
the best candidates for this study. First, because they display significantly different thermal SCO behavior and, second, because their crystal lattices do not suffer from efflorescence (i.e., solvent evaporation), as in the case of $\mathbf{1}\left(\mathrm{BF}_{4}\right)_{2} \cdot 4 \mathrm{MeNO}_{2}$ and $\mathbf{1}\left(\mathrm{BF}_{4}\right)_{2} \cdot \mathrm{H}_{2} \mathrm{O} \cdot 3 \mathrm{MeCN}$.

(a)

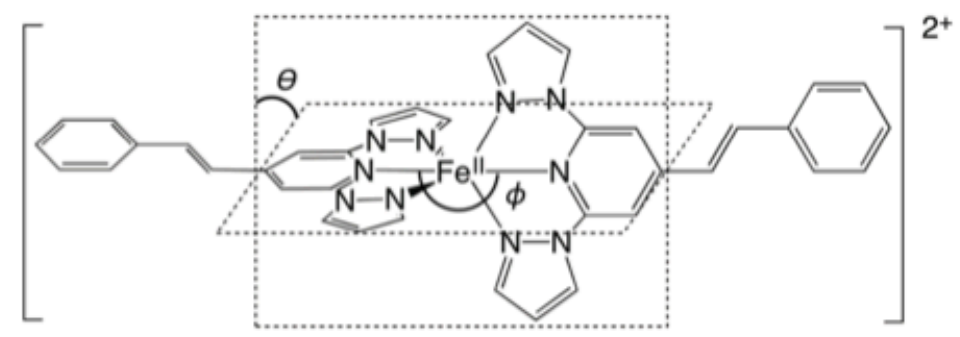

(b)

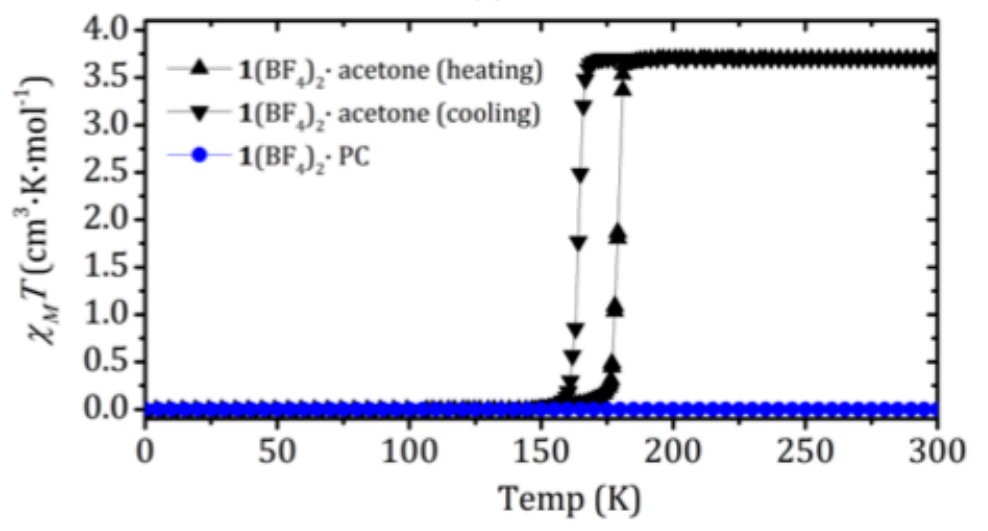

Figure 1. (a) Molecular structure of $\mathbf{1}$. The two angles represent the distortion of the ligands. $\Phi$ is the rotation of one ligand with respect to the other about the iron atom, and $\theta$ is the twist of the plane of one of the ligands about its $\mathrm{Fe}-\mathrm{N}$ (pyridine) bond. (b) Magnetic susceptibility $\left(\chi_{\mathrm{M}} T\right)$ curves over the $0-300 \mathrm{~K}$ temperature range of $\mathbf{1}\left(\mathrm{BF}_{4}\right)_{2} \cdot$ acetone and $\mathbf{1}\left(\mathrm{BF}_{4}\right)_{2} \cdot 2 \mathrm{PC}$. The data were extracted from ref 49 .

In the present paper, we analyze the impact of the crystal-solvent molecules on the SCO behavior of $\mathbf{1}\left(\mathrm{BF}_{4}\right)_{2}$ when the solvent molecules are either acetone or PC. By means of $\mathrm{DFT}+\mathrm{U}+\mathrm{D} 2$ calculations, we identify the sources that dictate the spin transition in the two polymorphs. In particular, we aim at giving an answer to the following questions: How important is the influence of the solvent molecules on the adiabatic energy gap (i.e., $\Delta H)$ ? What is the origin of this influence? Is it due to a structural distortion of the SCO molecules derived from the presence of solvent molecules? Is it due to the different amount of intermolecular interactions in each phase? Which kind of SCO behavior would present the two polymorphs upon desorption of the crystal-solvent molecules (dried polymorphs)? To answer these questions, we computed $\Delta H$ under different conditions and performed a thorough analysis of lattice stabilities. From our results, we conclude that the thermal SCO behavior of $\mathbf{1}\left(\mathrm{BF}_{4}\right)_{2}$ acetone is mostly dictated by the structural distortion of the $\mathrm{Fe}-\mathrm{N}_{6}$ coordination sphere suffered in the 
crystal, while intermolecular interactions do not contribute significantly to modulate $\Delta H$. On the contrary, the SCO behavior of $1\left(\mathrm{BF}_{4}\right)_{2} \cdot 2 \mathrm{PC}$ is mainly controlled by the different intermolecular interactions present in the crystal, whereas the structural changes of the SCO units are not relevant. More specifically, we found that the solventsolvent intermolecular interactions are decisive in preventing the SCO transition in $\mathbf{1}\left(\mathrm{BF}_{4}\right)_{2} \cdot 2 \mathrm{PC}$. Finally, our results indicate that the dried polymorphs would present an SCO behavior similar to that of the solvated crystals.

\section{RESULTS and DISCUSSION}

The presentation of the results is organized as follows. First, in Section 2.1, we compute the solid-state adiabatic energy gaps $\left(\Delta H_{\text {elec }}\right)$ of the $\mathbf{1}\left(\mathrm{BF}_{4}\right)_{2} \cdot$ acetone and $\mathbf{1}\left(\mathrm{BF}_{4}\right)_{2} \cdot 2 \mathrm{PC}$ polymorphs.

In Section 2.2, we analyze the adiabatic energy gaps of isolated SCO molecules $\left(\Delta H_{\text {elec }}{ }^{\text {iso(SCO) }}\right)$ considering both the HS and LS minima and the solid-state geometries. In Section 2.3, we analyze the effect that the structural distortions observed under the different environments studied (i.e., isolated or in solid state) have on $\Delta H_{\text {elec }}^{\text {iso(SCO). }}$ Finally, in Section 2.4, we perform an exhaustive analysis on the role of the intermolecular interactions in the SCO behavior of the different polymorphs of $\mathbf{1}$. We will use $\Delta H$ for all energy values obtained directly from a quantum-chemistry calculation and $\Delta E$ for all energy contributions to $\Delta H$. Both types of terms correspond to $\Delta X=X_{\mathrm{HS}}-X_{\mathrm{LS}}$. Therefore, a positive (negative) value implies a larger contribution to the stability of the LS (HS) state. Notice that we do not take into account the vibrational contribution to enthalpy $\left(\Delta H_{\mathrm{vib}}\right)$. This contribution has the effect of stabilizing the HS state, and it is usually evaluated using the vibrational normal modes of an isolated SCO molecule in the LS and HS states within the harmonic approximation.(12, 39, 50) Under these approximations, and since we will be comparing the same molecule (1) in different environments, $\Delta H_{\mathrm{vib}}$ would not have an impact in the relative stability of the two crystals (acetone vs PC). For similar reasons, entropy was neglected from the analysis that follows. Finally, all values are given per molecule of $\mathbf{1}\left(\mathrm{BF}_{4}\right)_{2} \cdot \mathrm{X}$.

\subsection{Adiabatic Gaps of the Polymorphs of $1\left(\mathrm{BF}_{4}\right)_{2} \cdot \mathrm{X}$}

Experimentally, it was observed that the thermal SCO behavior of 1 can be controlled by means of changing the solvent in single crystals of $1\left(\mathrm{BF}_{4}\right)_{2} \cdot \mathrm{X}(\mathrm{X}=$ crystal-solvent molecules). As mentioned in the Introduction, a complete SCO transition with a small hysteresis loop was observed for $1\left(\mathrm{BF}_{4}\right)_{2} \cdot$ acetone $\left(T_{1 / 2 \downarrow}=164 \mathrm{~K}, T_{1 / 2 \uparrow}=179 \mathrm{~K}, T_{1 / 2}=15\right.$ $\mathrm{K})$. On the contrary, $\mathbf{1}\left(\mathrm{BF}_{4}\right)_{2} \cdot 2 \mathrm{PC}$ displays diamagnetic response up to $300 \mathrm{~K}$. To determine the structural and electronic features that originate this different magnetic behavior for the same SCO unit, we first computed the adiabatic energy differences (i.e., $\left.\Delta H_{\text {elec }}\right)$ between the LS and HS states of $\mathbf{1}\left(\mathbf{1}^{\mathrm{LS}}\right.$ and $\left.\mathbf{1}^{\mathrm{HS}}\right)$ in the two solid-state environments. The initial nuclear coordinates were extracted from the available 
crystallographic data. For $\mathbf{1}\left(\mathrm{BF}_{4}\right)_{2}$ acetone, from the low-temperature (LT) and hightemperature (HT) crystal structures resolved at 150 and $190 \mathrm{~K}$, respectively, and, for $1\left(\mathrm{BF}_{4}\right)_{2} \cdot 2 \mathrm{PC}$, from the LT and HT X-ray coordinates reported at 113 and $283 \mathrm{~K}$. Note that the $1\left(\mathrm{BF}_{4}\right)_{2} \cdot 2 \mathrm{PC}$ structure resolved at $283 \mathrm{~K}$ was taken as the initial geometry for its HS optimization, although it also corresponds to an LS state. We are, thus, assuming that the two phases will share the same crystal packing in terms of symmetry group and molecular orientation. On one hand, $\mathbf{1}\left(\mathrm{BF}_{4}\right)_{2}$ acetone crystallizes in the $P 2_{1} / c$ space group, and its unit cell contains four 1 , eight $\mathrm{BF}_{4}^{-}$, and four acetone molecules both in the LT and HT phases. On the other, $\mathbf{1}\left(\mathrm{BF}_{4}\right)_{2} \cdot 2 \mathrm{PC}$ crystallizes in the $C 2 / c$ space group, with four 1, eight $\mathrm{BF}_{4}^{-}$, and eight $\mathrm{PC}$ molecules in its unit cell.

The resulting $\Delta H_{\text {elec }}$ values are collected in Table 1 and correspond to 5.3 and 25.4 $\mathrm{kJ} / \mathrm{mol}$ for $\mathbf{1}\left(\mathrm{BF}_{4}\right)_{2} \cdot$ acetone and $\mathbf{1}\left(\mathrm{BF}_{4}\right)_{2} \cdot 2 \mathrm{PC}$, respectively. The results are in agreement with the experimental evidence: a significantly larger $\Delta H_{\text {elec }}$ for $\mathbf{1}\left(\mathrm{BF}_{4}\right)_{2} \cdot 2 \mathrm{PC}$, responsible for a shift of the spin transition to higher temperatures (according to experiments, it occurs at a temperature higher than $300 \mathrm{~K}$ ). The phase transition of $\mathbf{1}\left(\mathrm{BF}_{4}\right)_{2} \cdot$ acetone was characterized by means of differential scanning calorimetry (DSC) experiments, with a $\Delta H$ value of $10.0(11.0) \mathrm{kJ} / \mathrm{mol}$ at $163 \mathrm{~K}(182 \mathrm{~K})$ in the cooling (heating) mode. Although the computed $\Delta H_{\text {elec }}$ is not directly comparable to the experimental $\Delta H$ value ( $\Delta H_{\mathrm{vib}}$ is missing, see discussion above), we note that our computed $\Delta H_{\text {elec }} 5.3 \mathrm{~kJ} / \mathrm{mol}$ underestimates the adiabatic gap, suggesting that a smaller $U$ parameter should be applied in the DFT $+U$ calculations to obtain better quantitative agreement. Notice that this underestimation is related to the accuracy in the description of 1 and, thus, does not affect the comparison of the two systems. Also, it does not affect the analysis of the intermolecular interactions done below.

Table 1. Absolute Unit-Cell Energies (in Ry) and Adiabatic Energy Gaps (in $\mathrm{kJ} / \mathrm{mol}$ ) Associated to the Spin Transition of $\mathbf{1}\left(\mathrm{BF}_{4}\right)_{2}$ in the Two Studied Polymorphs with (i.e., solvated) and without (i.e., dried) Crystal-Solvent Molecules

\begin{tabular}{c|cc|cc}
\hline \multirow{2}{*}{ Minimum } & \multicolumn{2}{|c|}{$\mathbf{1}\left(\mathrm{BF}_{4}\right)_{2} \cdot$ acetone } & \multicolumn{2}{c}{$\mathbf{1}\left(\mathrm{BF}_{4}\right)_{2} \cdot \mathbf{2 P C}$} \\
& solvated & dried & solvated & dried \\
\hline LS & -5589.8056 & -5296.1378 & -6487.8140 & -5296.1005 \\
HS & -5589.7894 & -5296.1252 & -6487.7366 & -5295.9977 \\
\hline$\Delta H_{\text {elec }}$ & 5.3 & 4.1 & 25.4 & 33.7
\end{tabular}

It was shown that the crystal-solvent molecules in $\mathbf{1}\left(\mathrm{BF}_{4}\right)_{2} \cdot$ acetone and $\mathbf{1}\left(\mathrm{BF}_{4}\right)_{2} \cdot 2 \mathrm{PC}$ do not desorb up to $300 \mathrm{~K}$. However, it is interesting to explore what would occur upon their removal yielding the dried (i.e., solvent free) $\mathbf{1}\left(\mathrm{BF}_{4}\right)_{2}$ crystals. The analysis of these solvent-free crystals gives us the opportunity to study the same compound (i.e., $\left.\mathbf{1}\left(\mathrm{BF}_{4}\right)_{2}\right)$ in two different polymorphs. To do so, we reoptimized the HS and LS phases of $1\left(\mathrm{BF}_{4}\right)_{2} \cdot$ acetone and $\mathbf{1}\left(\mathrm{BF}_{4}\right)_{2} \cdot 2 \mathrm{PC}$ but without the crystal-solvent molecules in the 
crystal. Therefore, in these calculations all unit cells consist of four 1 SCO molecules and eight $\left(\mathrm{BF}_{4}\right)^{-}$counterions. The $\Delta H_{\text {elec }}$ values obtained are collected in Table 1. Relatively small differences are obtained with respect to the corresponding solventcontaining materials, and, thus, a similar thermal-SCO behavior would be expected for the dried $\mathbf{1}\left(\mathrm{BF}_{4}\right)_{2}$ polymorphs. According to our results, the spin transition would be shifted toward smaller $T_{1 / 2}$ values upon solvent evaporation in the acetone-containing polymorph (5.3 vs $4.1 \mathrm{~kJ} / \mathrm{mol})$. On the contrary, a shift toward higher $T_{1 / 2}$ is predicted for $\mathbf{1}\left(\mathrm{BF}_{4}\right)_{2}$ after crystal-solvent desorption from $\mathbf{1}\left(\mathrm{BF}_{4}\right)_{2} \cdot 2 \mathrm{PC}(25.4 \mathrm{vs} 33.7 \mathrm{~kJ} / \mathrm{mol})$. Under these conditions, the energetics of the two solvent-free polymorphs can be now easily compared, given that they have the same chemical composition. The absolute energy of the polymorphs suggests that the solvent-free $\mathbf{1}\left(\mathrm{BF}_{4}\right)_{2} \cdot$ acetone crystal packing would be much more stable than the solvent-free $1\left(\mathrm{BF}_{4}\right)_{2} \cdot 2 \mathrm{PC}$, for both the LS $(-5296.1378 \mathrm{Ry}$ vs $-5296.1005 \mathrm{Ry}, \Delta E=12.2 \mathrm{~kJ} / \mathrm{mol})$ and HS phases $(-5296.1252 \mathrm{Ry}$ vs $-5295.9977 \mathrm{Ry}, \Delta E=41.8 \mathrm{~kJ} / \mathrm{mol})$. Then, one can hypothesize that a thermodynamically driven crystallization of $\mathbf{1}\left(\mathrm{BF}_{4}\right)_{2}$ would yield the $\mathbf{1}\left(\mathrm{BF}_{4}\right)_{2}$ acetone polymorph, thus showing a thermal SCO transition.

At this point, one must realize that the different relative stability between $\mathbf{1}^{\mathrm{HS}}$ and $\mathbf{1}^{\mathrm{LS}}$, in all the inspections performed so far, depends (i) on the geometry of the individual SCO molecules, which includes the ligand field splitting and intramolecular interactions, and (ii) on the intermolecular interactions that arise due to the crystal packing in the different polymorphs. These two effects are evaluated in the following sections.

\subsection{Adiabatic Gaps of 1 in the Gas-Phase and Solid-State Minima}

To establish a reference value for the intrinsic HS-LS relative stability of 1, we performed geometry-optimization calculations on the isolated molecule for its $\operatorname{LS}$ ( $S=$ $0)$ and HS $(S=2)$ states. The initial nuclear coordinates were extracted from the same LT and HT crystallographic data of $\mathbf{1}\left(\mathrm{BF}_{4}\right)_{2}$ acetone and $\mathbf{1}\left(\mathrm{BF}_{4}\right)_{2} \cdot 2 \mathrm{PC}$ indicated in the previous section. The two LT structures lead to the same minimum-energy geometry for 1, in which the ligands display a regular conformation, characterized by $\theta$ and angles $\phi$ typical of the pseudo-octahedral coordination $\left(90^{\circ}\right.$ and $180^{\circ}$, respectively; see Figure 1$)$. However, two different HS minimum-energy structures were obtained depending on whether the initial geometry corresponds to the $190 \mathrm{~K}-1\left(\mathrm{BF}_{4}\right)_{2}$ acetone or the $283 \mathrm{~K}$ $\mathbf{1}\left(\mathrm{BF}_{4}\right)_{2} \cdot 2 \mathrm{PC}$ polymorphs. These two different minima correspond to a distorted (dis) and a regular (reg) HS coordination geometries, respectively, the latter being $1.1 \mathrm{~kJ} / \mathrm{mol}$ more stable. The existence of one regular LS and two almost-degenerated HS minima in

gas-phase conditions was already predicted in previous work for $\left.\mathrm{Fe}(\mathrm{dpp})_{2}{ }^{2+},{ }^{2}, 51,52\right)$ hereafter referred to as $\mathbf{2}$. Complex 2 displays the same Fe-N coordination sphere as that of 1, but it lacks the styryl groups attached to the pyridine rings. Therefore, and assuming that the styryl groups are not highly relevant (see Section S2), a similar SCO behavior in gas-phase conditions would be expected for $\mathbf{1}$ and $\mathbf{2}$. The resulting HS-LS 
adiabatic gap for the isolated $\mathbf{1}^{\mathrm{HS}}$ and $\mathbf{1}^{\mathrm{LS}}$ minima $\left(\Delta H_{\text {elec }}\right)$ is 11.8 or $12.9 \mathrm{~kJ} / \mathrm{mol}$ depending on whether $\mathbf{1}^{\mathrm{HS}}$-reg or $\mathbf{1}^{\mathrm{HS}}$-dis are considered (see Table 2). The difference between both values $(1.1 \mathrm{~kJ} / \mathrm{mol})$ agrees with the difference found for $2(0.8$ $\mathrm{kJ} / \mathrm{mol}(15)$ ). Interestingly, the values found for $\mathbf{1}$ lie between those obtained in solidstate conditions (5.3 and $25.4 \mathrm{~kJ} / \mathrm{mol}$; see Table 1 ). This means that the crystal packing has the opposite effect on $\Delta H_{\text {elec }}$ when either acetone or $2 \mathrm{PC}$ is used as solvent. For the former, $\Delta H_{\text {elec }}$ is reduced, while for the latter it is increased.

Table 2. Absolute Energies (in Ry) and Adiabatic Energy Gap ( $\Delta H_{\text {elec }}$, in $\left.\mathrm{kJ} / \mathrm{mol}\right)$ of $\mathbf{1}$, Obtained in Gas-Phase Conditions

\begin{tabular}{|c|c|c|c|c|}
\hline Minima & Energy & Minima & Energy & $\Delta H_{\text {elec }}^{\text {iso }(S C O)}$ \\
\hline \multirow{2}{*}{$\mathbf{1}^{\text {LS }}$-reg } & \multirow{2}{*}{-919.2738} & $\mathbf{1}^{\mathrm{HS}}-$ dis & -919.2640 & 12.9 \\
\cline { 3 - 5 } & & $\mathbf{1}^{\mathrm{HS}}-$ reg & -919.2648 & 11.8 \\
\hline
\end{tabular}

a Note that two HS conformers exist, and, consequently, two possible $\Delta H_{\text {elec }}$ are considered.

The presence of solvent molecules and counterions in the lattice may induce a structural change in the SCO molecules. To evaluate their influence on $\Delta H_{\text {elec }}$, we computed the energy of the isolated SCO molecules in their solid-state optimized structures but in gas-phase conditions. In other words, we preserve the solid-state structure of the SCO units, and we eliminate any influence of intermolecular interactions on $\Delta H_{\text {elec }}$. This allows us to establish a direct correlation between the nuclear deformations of the SCO molecules and $\Delta H_{\text {elec }}$. Note that, due to symmetry reasons inherent to the $P 2_{1} / c$ space group, all SCO units within a unit cell are structurally equivalent; hence, a single SCO unit is representative of the four molecules. The HS-LS energy differences of the studied structures are given in Table 3. The $\Delta H_{\text {elec }}{ }^{\text {iso(SCO) }}$ value obtained for the isolated molecule of 1 extracted from the $\mathbf{1}\left(\mathrm{BF}_{4}\right)_{2} \cdot$ acetone crystal is only $0.4 \mathrm{~kJ} / \mathrm{mol}$ smaller than its solid-state $\Delta H_{\text {elec }}$ value $(4.9$ vs $5.3 \mathrm{~kJ} / \mathrm{mol})$. This indicates that intermolecular interactions are almost irrelevant in shaping $\Delta H_{\text {elec }}$ in $\mathbf{1}\left(\mathrm{BF}_{4}\right)_{2} \cdot$ acetone, so the relative stability of the HS and LS states is largely determined by the molecular geometry. In turn, the calculations performed for the isolated molecule extracted from the PCcontaining crystal reveal important changes with respect to the solid state (11.8 vs 25.4 $\mathrm{kJ} / \mathrm{mol}$ ). This means that the intermolecular interactions play a significant role in the relative stability of the LS and HS solid-state minima of $1\left(\mathrm{BF}_{4}\right)_{2} \cdot 2 \mathrm{PC}$. 
Table 3. Absolute Energies (in Ry) of the Isolated Molecules in the Different SolidState LS and HS Minima, and the Associated $\Delta H_{\text {elec }}{ }^{\text {iso(SCO) }}$ (in $\mathrm{kJ} / \mathrm{mol}$ )

\begin{tabular}{lccccc} 
& \multicolumn{2}{c}{$1\left(\mathrm{BF}_{4}\right)_{2}$-acetone } & & \multicolumn{2}{c}{$1(\mathrm{BF} 4)_{2} 2 \mathrm{PC}$} \\
\cline { 2 - 3 } \cline { 5 - 6 } minimum & solvated & dried & & solvated & dried \\
LS & -919.2476 & -919.2531 & & -919.2622 & -919.2579 \\
HS & -919.2438 & -919.2443 & & -919.2532 & -919.2547 \\
$\Delta H_{\text {elec }}^{\text {iso }(\mathrm{SCO})}$ & 4.9 & 11.6 & & 11.8 & 16.0
\end{tabular}

The absolute energies reported in Table 3 are useful to establish the relative stability of $\mathbf{1}^{\mathrm{HS}}$ and $\mathbf{1}^{\mathrm{LS}}$ in the different solid-state structures. These values can be further compared with the energy of the gas-phase optimized structures (see Table 2), which is the most stable geometries of $\mathbf{1}^{\mathrm{HS}}$ and $\mathbf{1}^{\mathrm{LS}}$. In doing so, we can evaluate how the structural deformations affect the stability of these species and, thus, $\Delta H_{\text {elec. }}$ In the case of $\mathbf{1}\left(\mathrm{BF}_{4}\right)_{2} \cdot 2 \mathrm{PC}$, it can be seen that both $\mathbf{1}^{\mathrm{HS}}$ and $\mathbf{1}^{\mathrm{LS}}$ are destabilized, with respect to its minimum, by exactly the same amount $(-919.2648$ vs -919.2532 Ry for HS state, and -919.2738 vs $-919.2622 \mathrm{Ry}$ for LS state, $\Delta E=15.2 \mathrm{~kJ} / \mathrm{mol}$; see Figure 2$)$. On the contrary, in the case of $\mathbf{1}\left(\mathrm{BF}_{4}\right)_{2} \cdot$ acetone, the LS state is more destabilized ( $-919.2738 \mathrm{vs}$ $-919.2476 \mathrm{Ry}, \Delta E=34.4 \mathrm{~kJ} / \mathrm{mol})$ than the HS state $(-919.2640 \mathrm{vs}-919.2438 \mathrm{Ry}, \Delta E=$ $26.4 \mathrm{~kJ} / \mathrm{mol}$ ) due to geometrical distortions (see Figure 2).

We will immediately analyze the reasons behind this observation but, for the sake of clarity, we will first perform the same analysis for the dried $\mathbf{1}\left(\mathrm{BF}_{4}\right)_{2}$ polymorphs (see Figure 2). We previously discussed that, according to our calculations, solvent-free and solvent-containing materials would display a similar thermal SCO transition. Interestingly, the analysis of $\Delta H_{\mathrm{elec}}{ }^{\text {iso(SCO) }}$ suggests that such behavior is originated by different solid-state effects acting in opposite directions in the case of the solvent-free $\mathbf{1}\left(\mathrm{BF}_{4}\right)_{2} \cdot$ acetone polymorph. We can observe a large difference between $\Delta H_{\text {elec }}$ iso(SCO) and $\Delta H_{\text {elec }}(11.6 \mathrm{vs} 4.1 \mathrm{~kJ} / \mathrm{mol}$, respectively). This is in contrast to what is observed for the solvent-containing material $\left(\Delta H_{\text {elec }}^{\text {iso(SCO) }}\right.$ and $\Delta H_{\text {elec }}$ are 4.9 vs $5.3 \mathrm{~kJ} / \mathrm{mol}$, respectively). The difference between each pair of values corresponds to the intermolecular interactions acting in each case. Therefore, one can see that these interactions stabilize the HS phase in the solvent-free system of the $\mathbf{1}\left(\mathrm{BF}_{4}\right)_{2}$-acetone polymorph $(\Delta E=-7.5 \mathrm{~kJ} / \mathrm{mol})$, whereas almost no effect is found for its solventcontaining analogue. On the contrary, the intermolecular interactions present in the solvent-free polymorph of $1\left(\mathrm{BF}_{4}\right)_{2} \cdot 2 \mathrm{PC}$ stabilize the LS state by $17.7 \mathrm{~kJ} / \mathrm{mol}$ $\left(\Delta H_{\text {elec }}\right.$ iso(SCO) and $\Delta H_{\text {elec }}$ are 16.0 vs $33.7 \mathrm{~kJ} / \mathrm{mol}$, respectively). The same trend is obtained for the solvent-containing material $\left(\Delta H_{\text {elec }}{ }^{\text {iso(SCO) }}\right.$ and $\Delta H_{\text {elec }}$ are 11.8 vs 25.4 $\mathrm{kJ} / \mathrm{mol}$, respectively), although it can be seen that its effect is slightly smaller. Overall, we conclude that the sum of collective crystal-packing effects, namely, the molecular distortions and the intermolecular interactions present in the solid-state, can tune the $\mathrm{SCO}$ behavior due to their different effect on $\Delta H_{\text {elec. }}$ 

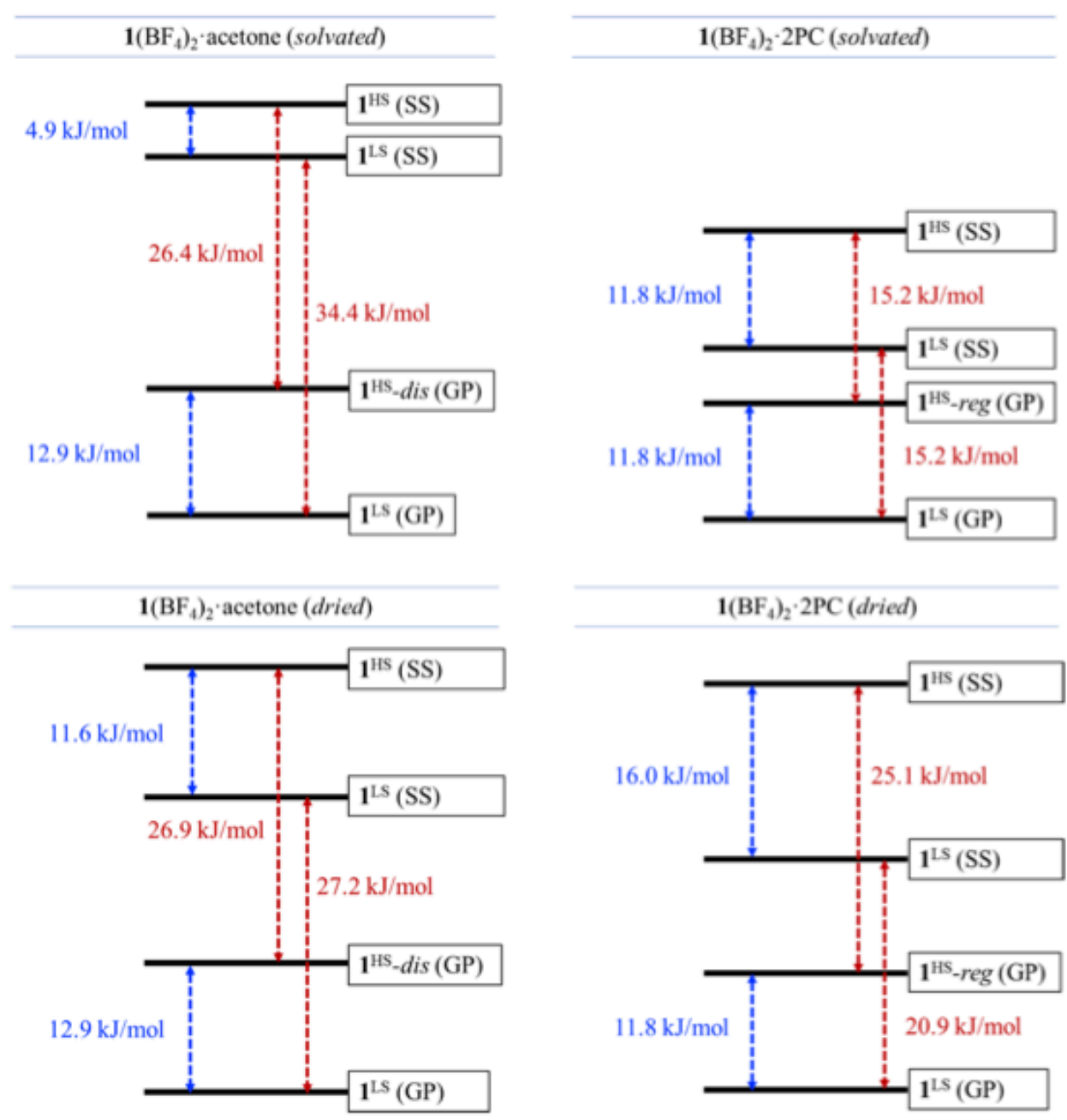

Figure 2. Scheme of the relative stability of the solid-state (SS) $\mathbf{1}^{\mathrm{HS}}$ and $\mathbf{1}^{\mathrm{LS}}$ structures in the solvated (top) and dried (bottom) minimum energy structures of $\mathbf{1}\left(\mathrm{BF}_{4}\right)_{2} \cdot$ acetone (left) and $\mathbf{1}\left(\mathrm{BF}_{4}\right)_{2} \cdot 2 \mathrm{PC}$ (right) compared to the gas-phase (GP) minima of $\mathbf{1}^{\mathrm{HS}}$ and $\mathbf{1}^{\mathrm{LS}}$. $\Delta H_{\text {elec }}{ }^{\text {iso(SCO) }}$ values are indicated in blue, and the energy penalties due to structural distortions are indicated in red.

\subsection{Effect of Geometry Distortions in the HS-LS Relative Stability of 1}

After evaluating the isolated HS-LS energy differences (i.e., $\Delta H_{\text {elec }}{ }^{\text {iso(SCO) }}$ ), we now analyze the ligand distortions that have an important effect on those energies. As previously mentioned, the degree of distortion of the $\mathrm{Fe}-\mathrm{N}_{6}$ coordination sphere is usually defined by $\theta$ and $\phi$ angles (see Figure 1), as well as by the Fe-N distances. The main structural parameters of the $\mathbf{1}^{\mathrm{HS}}$ and $\mathbf{1}^{\mathrm{LS}}$ minima in gas phase and in the solventcontaining and dried $1\left(\mathrm{BF}_{4}\right)_{2} \cdot$ acetone and $1\left(\mathrm{BF}_{4}\right)_{2} \cdot 2 \mathrm{PC}$ polymorphs are collected in Table S1 (see Supporting Information, Section S1). Overall, it can be observed that the SCO units in solid-state conditions present different degrees of distortion with respect to 
the minimum-energy structures obtained in gas phase depending on the polymorph. When considering $\mathbf{1}\left(\mathrm{BF}_{4}\right)_{2} \cdot 2 \mathrm{PC}$, both LS and HS SCO units display a regular disposition of the ligands, and only slightly smaller Fe-N distances $\theta$ and $\phi$ and angles are obtained. This would explain why $\Delta H_{\text {elec }}$ iso(SCO) remains almost unaffected with respect to the $\mathrm{HS}_{\text {reg }}$-LS energy difference between gas-phase minima (compare values in Tables 2 and 3). On the contrary, in the case of $1\left(\mathrm{BF}_{4}\right)_{2} \cdot$ acetone, both the LS and HS minima show largely distorted structures with $\theta$ values of ca. $68^{\circ}$ (see Table S1). As reported in the literature, ${ }^{(51)}$ the key prerequisite for the stability of the distorted structure is the population of the $e_{\mathrm{g}}$ set of antibonding orbitals, only achieved in the HS state. Therefore, such distortion implies a large penalty to the LS states, resulting in a much smaller $\Delta H_{\text {elec }}{ }^{\text {iso(SCO) }}$ (see Table 3). Certainly, the presence of an LS minimum displaying such ligand arrangement would be highly unexpected, given that it does not correspond to a minimum in gas-phase conditions. In fact, it was shown in previous work that the HS-to-LS SCO transition of $2\left(\mathrm{ClO}_{4}\right)_{2}$ was kinetically impeded due to the highly distorted environment of the HS SCO unit, while for $2\left(\mathrm{BF}_{4}\right)_{2}$, the spin transition was possible between both regular HS and LS conformers. ${ }^{(15)}$ Interestingly, in the present case the LS-to-HS transition is only reported to occur between LS and HS distorted conformers (case of $\mathbf{1}\left(\mathrm{BF}_{4}\right)_{2}$-acetone), whereas the regular ligand environment prevents the spin transition up to $300 \mathrm{~K}$ (case of $1\left(\mathrm{BF}_{4}\right)_{2} \cdot \mathrm{PC}$ ). Another difference is that the transition is thermodynamically unfavorable, not kinetically blocked as in the case of 2.

Finally, we studied whether the change in planarity of the styryl groups attached to the pyridines can have an effect on $\Delta H_{\text {elec }}$ (and on $\Delta H_{\text {elec }}{ }^{\text {iso(SCO) }}$ ). This study was prompted by the recent report that the change in the planarity of the $\pi$-system, upon HS-to-LS transition in $\left[\mathrm{Fe}^{\mathrm{II}}(\mathrm{Ph} 1,3 \mathrm{bpp})_{2}\right]$, was responsible for the destabilization of its LS state, and, as a consequence, its spin transition was thermodynamically blocked. ${ }^{(11)}$ The analysis, detailed in Section S2, shows that electronically innocent structural distortions (such as the styryl rotation) can play a role in the SCO transition. However, in the case under study this effect is rather small $(1-6 \mathrm{~kJ} / \mathrm{mol})$, thus indicating its minor role in the SCO transition.

\subsection{Effect of the Intermolecular Interactions in the HS-LS Relative Stability}

As previously mentioned, the calculated solid-state $\Delta H_{\text {elec }}$ values not only depend on the geometries of the SCO units under the effect of the crystal packing but also on the different intermolecular interactions that are established in the LS and HS minima $\left(E_{\text {int }}\right)$. The effect of the latter can be determined as the difference between $\Delta H_{\text {elec }}$ values obtained in solid state and in gas-phase, which are provided in Tables 1 and 3, respectively. Notice that $\Delta E_{\text {int }}$ quantifies the differential effect of all possible types of interactions between SCO molecules, counterions (CI), and solvent molecules (X) in the relative stability of $\mathbf{1}^{\mathrm{HS}}$ and $\mathbf{1}^{\mathrm{LS}}$ (eq 1 ). 


$$
\Delta E_{\text {int }}=\Delta E_{\text {int }}^{S C O-S C O}+\Delta E_{\text {int }}^{S C O-C I}+\Delta E_{\text {int }}^{S C O-X}+\Delta E_{\text {int }}^{C l-C I}+\Delta E_{\text {int }}^{C I-X}+\Delta E_{\text {int }}^{X-X}
$$

The $\Delta E_{\text {int }}$ values obtained for the solvent-containing polymorphs are 0.4 and 13.6 $\mathrm{kJ} / \mathrm{mol}$ for $\mathrm{X}=$ acetone and $\mathrm{X}=2 \mathrm{PC}$, respectively. For both materials, the positive sign indicates that the LS state is effectively being stabilized in the solid state due to intermolecular interactions. From their magnitude, it can be seen that these do not play a significant role for $1\left(\mathrm{BF}_{4}\right)_{2}$ acetone $\left(\Delta E_{\text {int }}=0.4 \mathrm{~kJ} / \mathrm{mol}\right)$ but are crucial in the HS-LS relative stability of $1\left(\mathrm{BF}_{4}\right)_{2} \cdot 2 \mathrm{PC}\left(\Delta E_{\text {int }}=13.6 \mathrm{~kJ} / \mathrm{mol}\right)$, ultimately preventing the thermal SCO transition to the HS state. For the solvent-free $\mathbf{1}\left(\mathrm{BF}_{4}\right)_{2}$ acetone and $\mathbf{1}\left(\mathrm{BF}_{4}\right)_{2} \cdot 2 \mathrm{PC}$ optimized polymorphs, the $\Delta E_{\text {int }}$ values are -7.5 and $17.7 \mathrm{~kJ} / \mathrm{mol}$, respectively. Comparing the two sets of results (solvent-containing vs solvent-free), it can be inferred that the role of the intermolecular interactions increases in the absence of crystal-solvent molecules. However, it is interesting to notice that their contribution is the opposite: the HS state becomes importantly stabilized by means of intermolecular interactions upon solvent removal in $1\left(\mathrm{BF}_{4}\right)_{2}$ acetone $\left(\Delta E_{\text {int }}\right.$ goes from 0.4 to -7.5 $\mathrm{kJ} / \mathrm{mol})$, whereas the LS state is stabilized in the dried $\mathbf{1}\left(\mathrm{BF}_{4}\right)_{2} \cdot 2 \mathrm{PC}$ crystal with respect to its solvated analogue ( $\Delta E_{\text {int }}$ goes from 13.6 to $\left.17.7 \mathrm{~kJ} / \mathrm{mol}\right)$. Because of the absence of solvent molecules, these values correspond to the sum of the terms: $\Delta E_{\mathrm{int}}{ }^{\mathrm{SCO}-\mathrm{SCO}}$, $\Delta E_{\mathrm{int}}^{\mathrm{SCO}-\mathrm{Cl}}$, and $\Delta E_{\mathrm{int}}^{\mathrm{CI}-\mathrm{Cl}}$. However, they cannot be directly compared to the $\Delta E_{\mathrm{int}}$ values of the solvated crystals, since they were obtained after variable-cell geometry optimizations and, thus, are subjected to the nuclear relaxation after removing the crystal-solvent molecules.

To have a meaningful comparison, we performed single-point (i.e., without further optimization) evaluations of the LS and $\mathrm{HS}$ energies of $1\left(\mathrm{BF}_{4}\right)_{2}$.acetone and $\mathbf{1}\left(\mathrm{BF}_{4}\right)_{2} \cdot 2 \mathrm{PC}$ at their solvent-containing minima but removing the crystal-solvent molecules. These calculations lead to $\Delta H_{\text {elec }}{ }^{\text {no-X }}$ values and allow us to determine the contributions of the solvent molecules and charged molecules (i.e., ions, SCO and CI) to the total $\Delta E_{\text {int }}$ (see eqs 2 and 3 and Computational Details section).

$$
\begin{aligned}
& \Delta H_{\text {elec }}-\Delta H_{\text {elec }}^{\mathrm{no}-\mathrm{X}}=\Delta E_{\text {int }}^{\mathrm{SCO}-\mathrm{X}}+\Delta E_{\text {int }}^{\mathrm{CI}-\mathrm{X}}+\Delta E_{\text {int }}^{\mathrm{X}-\mathrm{X}}=\Delta E_{\text {int }}^{\mathrm{SOLV}} \\
& \Delta H_{\text {elec }}^{\mathrm{no}-\mathrm{X}}-\Delta H_{\text {elec }}^{\mathrm{iso}(\mathrm{SCO})}=\Delta E_{\text {int }}^{\mathrm{SCO}-\mathrm{sCO}}+\Delta E_{\text {int }}^{\mathrm{SCO}-\mathrm{CI}}+\Delta E_{\text {int }}^{\mathrm{CI}-\mathrm{CI}}=\Delta E_{\text {int }}^{\mathrm{ION}}
\end{aligned}
$$

The resulting values are collected in Table 4. $\Delta E_{\text {elec }}{ }^{\text {no-X }}$ is 3.2 and $15.1 \mathrm{~kJ} / \mathrm{mol}$ for $\mathbf{1}\left(\mathrm{BF}_{4}\right)_{2} \cdot$ acetone and $\mathbf{1}\left(\mathrm{BF}_{4}\right)_{2} \cdot 2 \mathrm{PC}$, respectively, which implies that the solvent contribution through intermolecular interactions $\left(\Delta E_{\mathrm{int}}^{\mathrm{SOLV}}\right)$ is 2.1 and $10.3 \mathrm{~kJ} / \mathrm{mol}$ and, hence, that the nonsolvent intermolecular interactions $\left(\Delta E_{\mathrm{int}}^{\mathrm{ION}}\right)$ contribute by -1.7 and 
$3.3 \mathrm{~kJ} / \mathrm{mol}$ to $\Delta H_{\text {elec. }}$. As can be inferred from these results, both kinds of interactions (solvent and nonsolvent concerning) are of approximately the same magnitude but of opposite sign in $\mathbf{1}\left(\mathrm{BF}_{4}\right)_{2} \cdot$ acetone and, consequently, lead to a negligible overall effect on $\Delta H_{\text {elec }}$. Contrarily, they both stabilize the LS state in $1\left(\mathrm{BF}_{4}\right)_{2} \cdot 2 \mathrm{PC}$. Also, it is interesting to notice that $\Delta E_{\mathrm{int}}^{\mathrm{SOLV}}$ is much larger than $\Delta E_{\mathrm{int}}^{\mathrm{ION}}$. Note that the sign of $\Delta E_{\mathrm{int}}^{\mathrm{ION}}$ in the solvated crystals is in agreement with the $\Delta E_{\text {int }}$ values obtained for their corresponding solvent-free optimized polymorphs $(-1.7$ and $3.3 \mathrm{~kJ} / \mathrm{mol}$ for solvated $\mathbf{1}\left(\mathrm{BF}_{4}\right)_{2} \cdot$ acetone and $\mathbf{1}\left(\mathrm{BF}_{4}\right)_{2} \cdot 2 \mathrm{PC}$, respectively, vs -7.5 and $17.7 \mathrm{~kJ} / \mathrm{mol}$ for their corresponding dried polymorph). However, their magnitude increases significantly in the optimized dried polymorphs.

Table 4. Intermolecular Interaction Contributions ${ }^{\mathrm{a}}\left(\Delta E_{\text {int }}\right)$ to $\Delta H_{\text {elec }}$ (in $\mathrm{kJ} / \mathrm{mol}$ ), for the Solvent-Containing Crystals of $\mathbf{1}\left(\mathrm{BF}_{4}\right)_{2} \cdot$ acetone and $\mathbf{1}\left(\mathrm{BF}_{4}\right)_{2} \cdot 2 \mathrm{PC}$

\begin{tabular}{|c|c|c|}
\hline System & $\mathbf{1}\left(\mathrm{BF}_{4}\right)_{2} \cdot$ acetone & $\mathbf{1}\left(\mathrm{BF}_{4}\right)_{2} \cdot 2 \mathrm{PC}$ \\
\hline & solvated & solvated \\
\hline$\Delta E_{\text {int }}$ & 0.4 & 13.6 \\
\hline$\Delta E_{\text {int }}^{S C O-X}$ & $5.2^{*}$ & $14.2^{*}$ \\
\hline$\Delta E_{\text {int }}^{C I-X}$ & $-3.3^{*}$ & $-14.1^{*}$ \\
\hline$\Delta E_{\text {int }}^{X-X}$ & 0.2 & 10.2 \\
\hline$\Delta E_{\text {int }}^{S O L V}$ & 2.1 & 10.3 \\
\hline$\Delta E_{\text {int }}^{S C O-S C O}$ & 11.4 & 11.5 \\
\hline$\Delta E_{\text {int }}^{C I-C I}$ & -1.8 & -7.4 \\
\hline$\Delta E_{\text {int }}^{S C O C I}$ & -11.3 & -0.8 \\
\hline$\Delta E_{\text {int }}^{I O N}$ & -1.7 & 3.3 \\
\hline
\end{tabular}

a These values were analyzed in terms of solvent-related $\left(\Delta E_{\text {int }}{ }^{\mathrm{SOLV}}\right)$ and ion-ion $\left(\Delta E_{\text {int }}{ }^{\mathrm{ION}}\right)$ contributions (see eqs 2 and 3 ).

* Average values obtained from two different system of equations (see Computational Details).

So far, we considered for the solvated polymorphs the contribution of the intermolecular interactions concerning the solvent molecules $\left(\Delta E_{\mathrm{int}}^{\mathrm{SOLV}}\right)$ and considering only the ionion interactions $\left(\Delta E_{\text {int }}{ }^{\text {ION }}\right)$. However, the individual contribution of each pair of species present in the crystal has not been evaluated separately. In this context, the contribution of the solvent-solvent, SCO-SCO, and CI-CI intermolecular interactions $\left(\Delta E_{\mathrm{int}}^{\mathrm{X}}{ }^{\mathrm{X}}\right.$, $\left.\Delta E_{\mathrm{int}}^{\mathrm{SCO}-\mathrm{SCO}}, \Delta E_{\mathrm{int}}{ }^{\mathrm{CI}-\mathrm{CI}}\right)$ to the spin gap can be easily determined by means of computing the energies of the LS and HS phases removing all species but the crystal-solvent, the $\mathrm{SCO}$, or the CI molecules. Then, energy calculations involving the SCO and solvent (or the $\mathrm{CI}$ and solvent) molecules allow obtaining $\Delta E_{\text {int }}^{\mathrm{SCO}-\mathrm{X}}$ and $\Delta E_{\text {int }}{ }^{\mathrm{CI}-\mathrm{X}}$ contributions, while $\Delta E_{\mathrm{int}}^{\mathrm{SCO}-\mathrm{CI}}$ is inferred by difference (see Computational Details). All the values

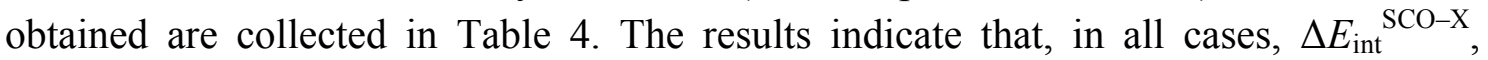
$\Delta E_{\mathrm{int}}^{\mathrm{SCO}-\mathrm{SCO}}$, and $\Delta E_{\mathrm{int}}^{\mathrm{X}-\mathrm{X}}$ favor the LS state, and $\Delta E_{\mathrm{int}}^{\mathrm{CI}-\mathrm{X}}, \Delta E_{\mathrm{int}}^{\mathrm{CI}-\mathrm{Cl}}$, and $\Delta E_{\mathrm{int}}{ }^{\mathrm{SCO}-\mathrm{CI}}$ 
stabilize the HS state. However, the different balance between their absolute values promotes more the LS stability for $1\left(\mathrm{BF}_{4}\right)_{2} \cdot 2 \mathrm{PC}$ than for $1\left(\mathrm{BF}_{4}\right)_{2} \cdot$ acetone polymorph. Regarding $\Delta E_{\mathrm{int}}^{\mathrm{SCO}-\mathrm{X}}$ and $\Delta E_{\mathrm{int}}^{\mathrm{CI}-\mathrm{X}}$, they approximately compensate each other for both systems $\left(5.2\right.$ and $-3.3 \mathrm{~kJ} / \mathrm{mol}$ for $1\left(\mathrm{BF}_{4}\right)_{2}$.acetone, and +14.2 and $-14.1 \mathrm{~kJ} / \mathrm{mol}$ for $\left.\mathbf{1}\left(\mathrm{BF}_{4}\right)_{2} \cdot 2 \mathrm{PC}\right)$, as well as all the ion-ion contributions $\left(\Delta E_{\mathrm{int}}{ }^{\mathrm{SCO}-\mathrm{SCO}}, \Delta E_{\mathrm{int}}{ }^{\mathrm{CI}-\mathrm{Cl}}\right.$, and $\Delta E_{\mathrm{int}}^{\mathrm{SCO}-\mathrm{CI}}$ are $11.4,-1.8$, and $-11.3 \mathrm{~kJ} / \mathrm{mol}$ for $1\left(\mathrm{BF}_{4}\right)_{2}$. acetone, and $11.5,-7.4$, and $-0.8 \mathrm{~kJ} / \mathrm{mol}$ for $\left.1\left(\mathrm{BF}_{4}\right)_{2} \cdot 2 \mathrm{PC}\right)$. On the contrary, the solvent-solvent interactions do not significantly contribute to $\Delta E_{\mathrm{int}}^{\mathrm{SOLV}}$ in $1\left(\mathrm{BF}_{4}\right)_{2}$. acetone $(0.2 \mathrm{~kJ} / \mathrm{mol})$, but remarkably, they imply a large contribution in $\mathbf{1}\left(\mathrm{BF}_{4}\right)_{2} \cdot 2 \mathrm{PC}(10.2 \mathrm{~kJ} / \mathrm{mol})$.

The different effect of the solvent-solvent interactions in modulating $\Delta H_{\text {elec }}$ can be well-understood by looking at the different relative disposition of the solvent molecules in the crystal of $\mathbf{1}\left(\mathrm{BF}_{4}\right)_{2} \cdot$ acetone and $\mathbf{1}\left(\mathrm{BF}_{4}\right)_{2} \cdot 2 \mathrm{PC}$. For the former, the four acetone molecules are individually distributed along the crystallographic unit cell, while for the latter, the eight PC molecules are organized in pairs. Therefore, minor changes in the cell do not imply a significant $\Delta E_{\text {int }}{ }^{\mathrm{X}} \mathrm{X}$ contribution for $\mathbf{1}\left(\mathrm{BF}_{4}\right)_{2} \cdot$ acetone, but they can entail a substantial variation for $\mathbf{1}\left(\mathrm{BF}_{4}\right)_{2} \cdot 2 \mathrm{PC}$. In particular, the four PC dimers display an interplanar distance of $3.52 \AA$, in the LS minimum (Figure $3 \mathrm{a}$ ), and of $3.97 \AA$ in the HS minimum (Figure $3 \mathrm{~b}$ ), following the different cavity provided by the LS and HS SCO units, respectively. The different arrangement of the solvent dimers is illustrated in Figure 3c. It can be seen that not only the distance $(d)$ between the PC molecules increase but also the slippage angle $(\alpha)$ is significantly modified when going from the LS to the HS crystal-minimum. The strong influence of these parameters in modulating the interaction energy between $\pi$-stacked molecules was already shown in previous work. ${ }^{(53)}$ To further validate this result, gas-phase calculations were performed for all PC dimers of the HS and LS minima. The difference in interaction energy (mean value) was found to be ca. $9 \mathrm{~kJ} / \mathrm{mol}(-41.7$ vs $-32.7 \mathrm{~kJ} / \mathrm{mol}$ for LS and HS dimers, respectively), whereas the difference in the energy was found to be of ca. $10.8 \mathrm{~kJ} / \mathrm{mol}$. This second value includes not only the difference in interaction energy but also the energy associated with the structural change of the solvent molecules $\left(\Delta E_{\text {elec }}{ }^{\text {iso(X); }}\right.$; see Computational Details). These inspections corroborate that the major decrease in lattice stability of the HS minimum of $\mathbf{1}\left(\mathrm{BF}_{4}\right)_{2} \cdot 2 \mathrm{PC}$, due to solvent-solvent intermolecular interactions, is originated in this particular structural rearrangement. 
(a)

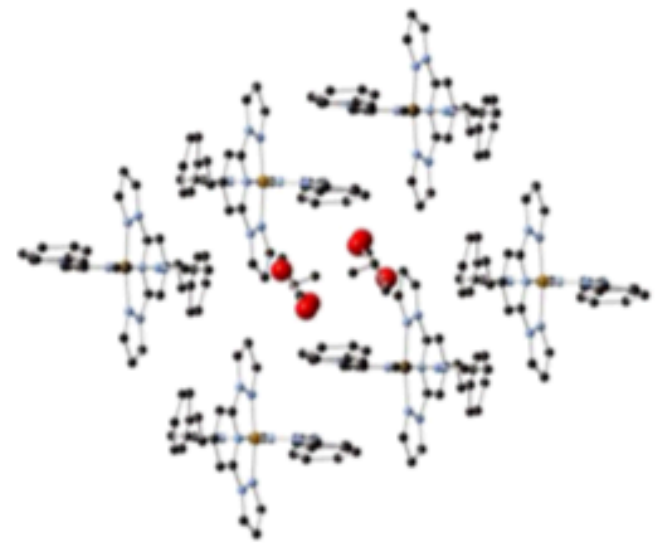

(c)

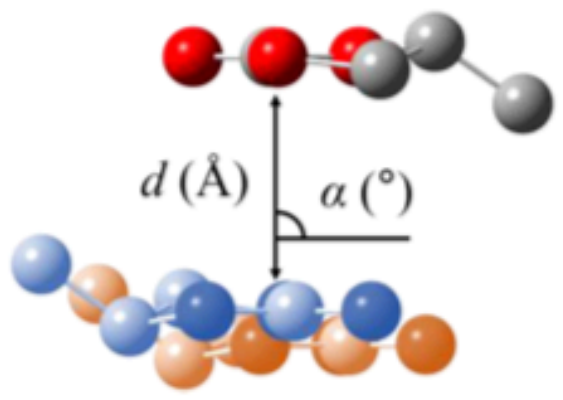

(b)

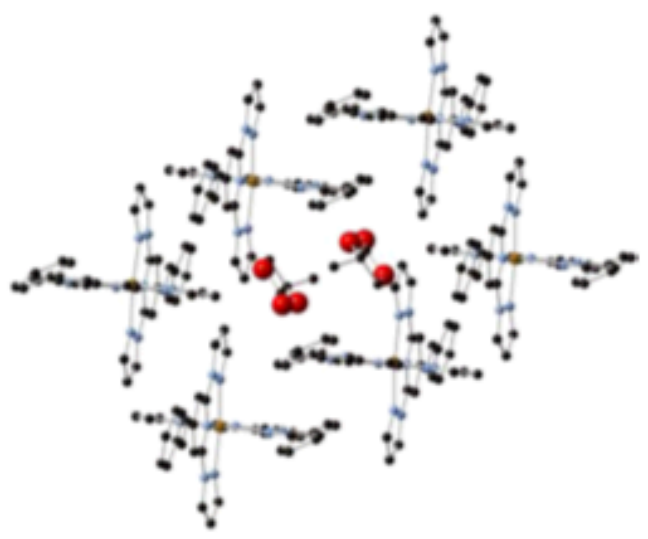

(d)

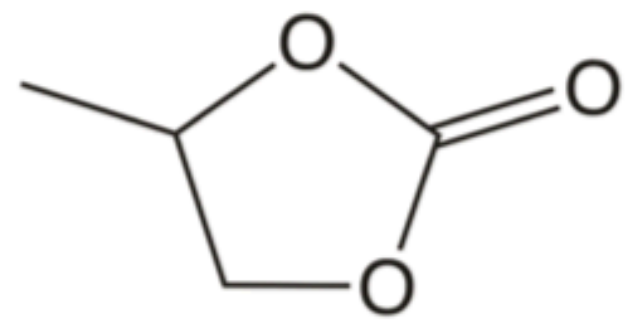

Figure 3. Representation of the solvent pairs surronded by six SCO units in $\mathbf{1}\left(\mathrm{BF}_{4}\right)_{2} \cdot 2 \mathrm{PC}$ crystal for (a) the LS minimum and (b) the HS minimum. For these images, the color code is $\mathrm{C}$ in black, $\mathrm{N}$ in pale blue, $\mathrm{O}$ in red, iron in brown. The superposition of both solvent-dimer structures is illustrated in (c), where the structure of the PC dimer in the LS minimum is highlighted in blue, and that of the HS structure is in orange. The top molecule is superimposed in both structures to facilitate the comparison. (d) Structure of the PC solvent molecules. Hydrogen atoms are hidden for clarity.

\section{COMPUTATIONAL DETAILS}

All energy evaluations were performed using the Quantum Espresso package (QE) Version 5.2, using the PBE+U scheme with a $U$ parameter of $2.65 \mathrm{eV}$ applied on the $\mathrm{d}$ orbitals of iron. We used the spin unrestricted formalism, the D2 correction of Grimme, ${ }^{(41)}$ Vanderbilt pseudopotentials, ${ }^{(54)}$ and a $\Gamma$-point sampling of the Brillouin zone. For the solid-state calculations, the minimum-energy structure of the HS and LS crystals of $1\left(\mathrm{BF}_{4}\right)_{2}$ acetone and $\mathbf{1}\left(\mathrm{BF}_{4}\right)_{2} \cdot 2 \mathrm{PC}$ (solvated and dried polymorphs) was obtained by performing successive variable-cell geometry relaxations. In this type of calculation, the lattice parameters and the atomic positions are optimized 
simultaneously. The convergence criterion was set at atomic forces smaller than $1 \times 10^{-}$ ${ }^{5}$ atomic units. In these calculations, the number of plane waves was kept constant at a kinetic energy cutoff of $70 \mathrm{Ry}$. This large cutoff ensures that artifacts originated in the change of unit-cell volume (i.e., Pulay stress) are negligible. The spin state of the iron atoms is set by defining an appropriate initial guess (LS or HS) that is maintained along the optimization. The final unit cell parameters are provided in Table S3, together with the experimental values. No significant changes are observed after optimization apart from the expected thermal contraction (the optimized structures can be understood as the $0 \mathrm{~K}$ crystal structures). For the gas-phase optimizations, the HS and LS minima $\left(1^{\mathrm{HS}}\right.$ and $\mathbf{1}^{\mathrm{LS}}$ ) were calculated in a cubic cell of $70 \mathrm{Bohr},{ }^{(3)}$ which ensures that the molecules are effectively isolated from their virtual counterparts. The Makov-Payne correction ${ }^{(55)}$ to energy was applied to account for the fact that the unit cells have a net charge. A kinetic energy cutoff of 35 Ry was used for these constant-cell calculations to reduce the computational cost. The same setup was used for the evaluation of the energy of $1^{\mathrm{HS}}$ and $\mathbf{1}^{\mathrm{LS}}$ (and $\mathbf{2}^{\mathrm{HS}}$ and $\mathbf{2}^{\mathrm{LS}}$ ) at the solid-state geometries but in isolated conditions, as well as for the evaluation of the difference in interaction energy between the isolated pairs of PC molecules of the LS and HS phases.

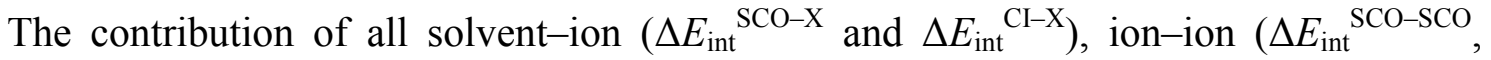
$\Delta E_{\text {int }}{ }^{\mathrm{CI}-\mathrm{CI}}$, and $\left.\Delta E_{\text {int }}^{\mathrm{SCO}-\mathrm{CI}}\right)$, and solvent-solvent $\left(\Delta E_{\text {int }}{ }^{\mathrm{X}-\mathrm{X}}\right)$ intermolecular interactions to the spin gap of the solvated polymorphs was determined by means of computing the energies of the LS and HS phases when removing different species in the unit cell. The computed energy differences $\left(\Delta H_{\text {elec }}\right)$ were used to obtain all the energy contributions by solving the following equations (eqs 4-9). Notice that we use $\Delta H$ for all energy values obtained directly from a quantum-chemistry calculation and $\Delta E$ for all energy contributions to the enthalpy differences.

$$
\begin{aligned}
& \Delta H_{\text {elec }}^{\text {only-SCO }}=\Delta E_{\text {int }}^{\mathrm{SCO}-\mathrm{SCO}}+\Delta H_{\text {elec }}^{\text {iso }(\mathrm{SCO})} \\
& \Delta H_{\text {elec }}^{\text {only-CI }}=\Delta E_{\text {int }}^{\mathrm{CI}-\mathrm{CI}}+\Delta H_{\text {elec }}^{\text {iso(CI) }} \approx \Delta E_{\text {int }}^{\mathrm{CI}-\mathrm{CI}} \\
& \Delta E_{\text {int }}^{\mathrm{SCO}-\mathrm{CI}}=\Delta E_{\text {int }}^{\mathrm{ION}}-\Delta E_{\text {int }}^{\mathrm{CI}-\mathrm{CI}}-\Delta E_{\text {int }}^{\mathrm{SCO}-\mathrm{SCO}} \\
& \Delta H_{\text {elec }}^{\text {only-X }}=\Delta E_{\text {int }}^{\mathrm{X}-\mathrm{X}}+\Delta H_{\text {elec }}^{\text {iso }(\mathrm{X})} \approx \Delta E_{\text {int }}^{\mathrm{X}-\mathrm{X}} \\
& \Delta H_{\text {elec }}-\Delta H_{\text {elec }}^{\mathrm{no}-\mathrm{CI}}=\Delta E_{\text {int }}^{\mathrm{SCO}-\mathrm{CI}}+\Delta E_{\text {int }}^{\mathrm{CI}-\mathrm{CI}}+\Delta E_{\text {int }}^{\mathrm{CI}-\mathrm{X}} \\
& \Delta H_{\text {elec }}-\Delta H_{\text {elec }}^{\mathrm{no}-\mathrm{SCO}} \\
& \quad=\Delta E_{\text {int }}^{\mathrm{SCO}-\mathrm{SCO}}+\Delta E_{\text {int }}^{\mathrm{SCO}-\mathrm{CI}}+\Delta E_{\text {int }}^{\mathrm{SCO}-\mathrm{X}}+\Delta E_{\text {int }}^{\text {iso }}
\end{aligned}
$$

$\Delta H_{\text {elec }}{ }^{\text {only-SCO }}, \Delta H_{\text {elec }}{ }^{\text {only-CI}}$, and $\Delta H_{\text {elec }}{ }^{\text {only-X }}$ correspond to the energy differences computed for unit cells including only the SCO, CI, or the solvent molecules. In the case of SCO molecules, there is an evident change in the molecular structure upon spin 
transition, and, thus, we explicitly evaluate its importance (through $\Delta H_{\text {elec }}{ }^{\text {iso(SCO) }}$ ) in $\Delta H_{\text {elec }}{ }^{\text {only-SCO }}$. In the case of counterion $\left(\Delta H_{\text {elec }}{ }^{\text {only-CI }}\right)$ and solvent molecules $\left(\Delta H_{\text {elec }}{ }^{\text {only- }}\right.$ $\mathrm{x})$, there is also a small change in their geometry between the HS and LS unit cells that would correspond to $\Delta H_{\mathrm{elec}}{ }^{\text {iso(CI) }}$ and $\Delta H_{\mathrm{elec}}{ }^{\text {iso(X) }}$. For simplicity, these contributions were included in $\Delta E_{\text {int }}^{\mathrm{CI}-\mathrm{CI}}$ and $\Delta E_{\mathrm{int}}{ }^{\mathrm{X}-\mathrm{X}}$, and they account for $-0.3 \mathrm{~kJ} / \mathrm{mol}$ in the case of $\Delta H_{\text {elec }}$ iso(CI) and $0.1 \mathrm{~kJ} / \mathrm{mol}$ (acetone) and $1.8 \mathrm{~kJ} / \mathrm{mol}(\mathrm{PC})$ in the case of $\Delta H_{\text {elec }}$ iso(X). In turn, $\Delta H_{\text {elec }}{ }^{\text {no-CI }}$ and $\Delta H_{\text {elec }}^{\text {no-SCO }}$ correspond to the energy differences obtained when removing the $\mathrm{CI}$ or the $\mathrm{SCO}$ molecules from the complete unit cell. Note that two different sets of values for $\Delta E_{\mathrm{int}}^{\mathrm{CI}-\mathrm{X}}$ and $\Delta E_{\text {int }}{ }^{\mathrm{SCO}-\mathrm{X}}$ can be obtained depending on whether one uses the calculated $\Delta H_{\text {elec }}{ }^{\text {no-CI }}$ or $\Delta H_{\text {elec }}{ }^{\text {no-SCO }}$ energy differences and eq 2. The values provided in Table 4 correspond to the average of both solutions, with standard deviations of 0.6 and $0.1 \mathrm{~kJ} / \mathrm{mol}$ for $\mathbf{1}\left(\mathrm{BF}_{4}\right)_{2}$ acetone and $\mathbf{1}\left(\mathrm{BF}_{4}\right)_{2} \cdot 2 \mathrm{PC}$, respectively. This small deviation must arise from the fact that we assume that all interactions can be treated separately, without potential screening or cooperative effects.

\section{CONCLUSIONS}

In the present paper, we have studied the thermal SCO behavior of two solvatomorphs of $\left[\mathrm{Fe}(E \text {-dpsp })_{2}\right]^{2+}$ complex (1) presenting a different spin transition. In particular, we have investigated the $\mathbf{1}\left(\mathrm{BF}_{4}\right)_{2} \cdot$ acetone and $\mathbf{1}\left(\mathrm{BF}_{4}\right)_{2} \cdot 2 \mathrm{PC}$ materials. The former displays cooperative SCO at $T_{1 / 2 \uparrow}=179 \mathrm{~K}\left(T_{1 / 2 \downarrow}=164 \mathrm{~K}\right)$, whereas the latter remains in the LS state up to $300 \mathrm{~K}$. By means of $\mathrm{DFT}+\mathrm{U}+\mathrm{D} 2$ calculations, we have investigated the reasons behind the two markedly distinct SCO behaviors. Being the solvent molecules the unique difference between both systems in terms of chemical composition, our study provides a thorough analysis of the crystal-solvent effects in these $\mathrm{Fe}(\mathrm{II})$-based SCO compounds. The computational evaluation of the HS-LS adiabatic gap $\left(\Delta H_{\text {elec }}\right)$ for the two systems indicates a significantly larger value for $1\left(\mathrm{BF}_{4}\right)_{2} \cdot 2 \mathrm{PC}$ with respect to $\mathbf{1}\left(\mathrm{BF}_{4}\right)_{2} \cdot$ acetone. This is in agreement with the experimental evidence. Interestingly, the $\Delta H_{\text {elec }}$ value obtained for 1 (i.e., in gas-phase conditions) is between those of $\mathbf{1}\left(\mathrm{BF}_{4}\right)_{2} \cdot 2 \mathrm{PC}$ and $\mathbf{1}\left(\mathrm{BF}_{4}\right)_{2} \cdot$ acetone. This indicates that the crystal-packing has the opposite effect on the spin gap. When using acetone, $\Delta H_{\text {elec }}$ is reduced, (leading to lower $T_{1 / 2}$ ), whereas PC contributes to increase $\Delta H_{\text {elec }}$ (shifting $T_{1 / 2}$ to values higher than $300 \mathrm{~K}$ ). This effect can be originated in molecular distortions triggered by the presence of the solvent molecules or by intermolecular interactions. Both contributions have been extensively analyzed.

Our results allow to conclude that the relative stability of the HS and LS states in $\mathbf{1}\left(\mathrm{BF}_{4}\right)_{2} \cdot$ acetone is largely determined by the molecular geometry adopted by the SCO units in the crystal. In the solid-state minimum of $\mathbf{1}\left(\mathrm{BF}_{4}\right)_{2} \cdot$ acetone, both $\mathbf{1}^{\mathrm{HS}}$ and $\mathbf{1}^{\mathrm{LS}}$ display a largely distorted $\mathrm{Fe}-\mathrm{N}_{6}$ coordination sphere. Interestingly, the presence of an LS minimum displaying a distorted ligand arrangement is remarkable given that it does not correspond to a minimum according to our gas-phase optimizations. As expected, such ligand distortion implies a larger energy penalty in the LS than in the HS state, 
resulting in a smaller $\Delta H_{\text {elec. }}$ Provided that the intermolecular interactions do not strongly contribute to $\Delta H_{\text {elec}}$, we can univocally ascribe the relatively low transition temperature of $1\left(\mathrm{BF}_{4}\right)_{2}$ acetone to the distorted environment of the SCO molecule. On the contrary, the intermolecular interactions play the primary role in the case of $\mathbf{1}\left(\mathrm{BF}_{4}\right)_{2} \cdot 2 \mathrm{PC}$. In the solid-state minimum of $\mathbf{1}\left(\mathrm{BF}_{4}\right)_{2} \cdot 2 \mathrm{PC}, \mathbf{1}^{\mathrm{HS}}$ and $\mathbf{1}^{\mathrm{LS}}$ present a regular structure, and their relative stability is equal to the $\Delta H_{\text {elec }}$ value obtained between the gas-phase minima. Therefore, the deformation of the SCO units in the crystal does not contribute to modulate $\Delta H_{\text {elec}}$, and its large value is originated in the different intermolecular interactions present in the HS and LS phases. A deep analysis of the contribution of the different intermolecular interactions that modulate $\Delta H_{\text {elec }}$ allows us to determine that the solvent-solvent interactions actively promote the LS stability. In particular, we found that this effect is originated in the formation of dimers of solvent molecules in the lattice. The same analysis was performed for the dried polymorphs, that is, without the crystal-solvent molecules in the lattices. The recomputed $\Delta H_{\text {elec }}$ values indicate that they would display a similar SCO behavior as that of the solventcontaining systems. Therefore, relatively small changes in $T_{1 / 2}$ would be expected upon solvent desorption in the studied systems. It is interesting to notice, however, that the lattice stabilities suggest that the dried $1\left(\mathrm{BF}_{4}\right)_{2}$ acetone polymorph would be more stable than the dried $\mathbf{1}\left(\mathrm{BF}_{4}\right)_{2} \cdot 2 \mathrm{PC}$ one. Remarkably, different crystal-packing effects are obtained for the dried polymorphs. In both cases, $\Delta H_{\text {elec }}$ is mainly governed by the intermolecular interactions; however, they promote the stability of opposite spin states. The HS state is favored in dried $\mathbf{1}\left(\mathrm{BF}_{4}\right)_{2}$-acetone, whereas the LS state gets stabilized in the dried $1\left(\mathrm{BF}_{4}\right)_{2} \cdot 2 \mathrm{PC}$ polymorph.

In summary, our study demonstrates that lattice-solvent molecules may modify the SCO of a given material through two possible contributions: (i) by inducing a geometrical distortion in the SCO units or (ii) by intermolecular interactions in the crystal. Interestingly, we show that the latter effect is not restricted to intermolecular interactions directly involving the SCO molecules, but it may also refer to interactions between spin-inactive species in the lattice. Overall, this is yet another proof of how subtle is the SCO behavior in Fe(II)-based complexes and that the smart use of latticesolvent molecules may be used to modulate their spin transition.

\section{Acknowledgements}

F.J.-G. and J.R.-A. acknowledge the Spanish Government for financial support (Project No. MAT2014-54025-P) and the Catalan DURSI (Grant No. 2014SGR1422). M.F. and S.V. acknowledge the ANR and the LabEx program for postdoctoral grants (No. ANR-10-LABX-0026_CSC). We also acknowledge the BSC and the regional HPC center in Strasbourg for the allocation of computer time. S.V. thanks Prof. V. Robert for fruitful discussions. 


\section{Supporting Information}

Structural parameters of the gas-phase and solid-state minima. Effect of the styryl group planarity on $\Delta H_{\text {elec }}$. Cartesian coordinates and unit cell parameters of the optimized crystal structures. Cartesian coordinates of the gas-phase minima. 


\section{References}

(1) Miyamachi, T.; Gruber, M.; Davesne, V.; Bowen, M.; Boukari, S.; Joly, L.; Scheurer, F.; Rogez, G.; Yamada, T. K.; Ohresser, P.; et al. Robust Spin Crossover and Memristance across a Single Molecule. Nat. Commun. 2012, 3, 938.

(2)Lefter,C.;Davesne,V.;Salmon,L.;Molnaŕ,G.;Demont,P.; Rotaru, A.; Bousseksou, A. Charge Transport and Electrical Properties of Spin Crossover Materials: Towards Nanoelectronic and Spintronic Devices. Magnetochemistry 2016, 2, 18.

(3) Frisenda, R.; Harzmann, G. D.; Celis Gil, J. A.; Thijssen, J. M.; Mayor, M.; van der Zant, H. S. J. Stretching-Induced Conductance Increase in a Spin-Crossover Molecule. Nano Lett. 2016, 16, 4733- 4737.

(4) Harzmann, G. D.; Frisenda, R.; van der Zant, H. S. J.; Mayor, M. Single-Molecule Spin Switch Based on Voltage-Triggered Distortion of the Coordination Sphere. Angew. Chem., Int. Ed. 2015, 54, 13425-13430.

(5) Bousseksou, A.; Molnar, G.; Salmon, L.; Nicolazzi, W. Molecular Spin Crossover Phenomenon: Recent Achievements and Prospects. Chem. Soc. Rev. 2011, 40, 3313-3335.

(6)Gütlich,P.;Goodwin,H.A.;Letard,J.-F.;Guionneau,P.;Goux- Capes, L. Towards Spin Crossover Applications. Spin Crossover in Transition Metal Compounds III; Springer: Berlin, Germany, 2004; Vol. 235, pp 1-19.

(7) Gütlich, P.; Garcia, Y.; Goodwin, H. A. Spin Crossover Phenomena in Fe(II) Complexes. Chem. Soc. Rev. 2000, 29, 419-427. (8) Shepherd, H. J.; Gural'skiy, I. y. A.; Quintero, $\quad$ C. M.; $\quad$ Tricard, S.; Salmon,L.;Molnaŕ,G.;Bousseksou,A.MolecularActuatorsDrivenby Cooperative SpinState Switching. Nat. Commun. 2013, 4, 1

DOI: 10.1038/ncomms3607. (9) Kershaw Cook, L. J.; Kulmaczewski, R.; Mohammed, R.; Dudley,

S.; Barrett, S. A.; Little, M. A.; Deeth, R. J.; Halcrow, M. A. A Unified Treatment of the Relationship between Ligand Substituents and Spin State in a Family of Iron(II) Complexes. Angew. Chem., Int. Ed. 2016, 55, 4327-4331.

(10) Vela, S.; Gourlaouen, C.; Fumanal, M.; Ribas-Arino, J. Disclosing the Ligand- and Solvent-Induced Changes on the Spin Transition and Optical Properties of Fe(II)indazolylpyridine Com- plexes. Magnetochemistry 2016, 2, 6.

(11) Bartual-Murgui, C.; Vela, S.; Roubeau, O.; Aromi, G. Designed Intramolecular Blocking of the Spin Crossover of an Fe(II) Complex. Dalton Trans. 2016, 45, $14058-14062$. 
(12) Vela, S.; Fumanal, M.; Ribas-Arino, J.; Robert, V. Towards an Accurate and Computationally-Efficient Modelling of Fe(II)-Based Spin Crossover Materials. Phys. Chem. Chem. Phys. 2015, 17, 16306-16314.

(13) Halcrow, M. A. Iron(II) Complexes of 2,6-Di(pyrazol-1-yl)pyridines-a Versatile System for Spin-Crossover Research. Coord. Chem. Rev. 2009, 253, 2493-2514.

(14) Craig, G. A.; Roubeau, O.; Aromí, G. Spin State Switching in 2,6-Bis(pyrazol-3yl)Pyridine(3-bpp)BasedFe(II)Complexes.Coord. Chem. Rev. 2014, 269, 13-31.

(15) Vela, S.; Novoa, J. J.; Ribas-Arino, J. Insights into the Crystal- Packing Effects on the Spin Crossover of [Fe(II)(1-bpp)]2+-Based Materials. Phys. Chem. Chem. Phys. 2014, 16, 27012-27024.

(16)Bonnet,S.;Molnaŕ,G.;SanchezCosta,J.;Siegler,M.A.;Spek, A. L.; Bousseksou, A.; Fu, W.-T.; Gamez, P.; Reedijk, J. Influence of Sample Preparation, Temperature, Light, and Pressure on the Two- Step Spin Crossover Mononuclear Compound [Fe(bapbpy) (NCS)2]. Chem. Mater. 2009, 21, 1123-1136.

(17) Craig, G. A.; Costa, J. S.; Roubeau, O.; Teat, S. J.; Aromí, G. Local Coordination Geometry and Spin State in Novel Fe(II) Complexes with 2,6-Bis(pyrazol-3yl)Pyridine-Type Ligands as Con- trolled by Packing Forces: Structural Correlations. Chem. - Eur. J. 2012, 18, 11703-11715.

(18) Wei, R.-J.; Tao, J.; Huang, R.-B.; Zheng, L.-S. Reversible and Irreversible VaporInduced Guest Molecule Exchange in Spin- Crossover Compounds. Inorg. Chem. 2011, $50,8553-8564$.

(19) Zhang, W.; Zhao, F.; Liu, T.; Yuan, M.; Wang, Z.-M.; Gao, S. Spin Crossover in a Series of Iron(II) Complexes of 2-(2-alkyl-2H- tetrazol-5-yl)-1,10-Phenanthroline: Effects of Alkyl Side Chain, Solvent, and Anion. Inorg. Chem. 2007, 46, 2541-2555.

(20) Hostettler, M.; Törnroos, K. W.; Chernyshov, D.; Vangdal, B.; Bürgi, H.-B. Challenges in Engineering Spin Crossover: Structures and Magnetic Properties of Six Alcohol Solvates of Iron(II) Tris(2- picolylamine) Dichloride. Angew. Chem., Int. Ed. 2004, 43, 4589-4594.

(21)Costa,J.S.;Rodríguez-Jimeńez,S.;Craig,G.A.;Barth,B.; Beavers, C. M.; Teat, S. J.; Aromí, G. Three-Way Crystal-to-Crystal Reversible Transformation and Controlled Spin Switching by a Nonporous Molecular Material. J. Am. Chem. Soc. 2014, 136, $3869-3874$.

(22) Gentili, D.; Demitri, N.; Schafer, B.; Liscio, F.; Bergenti, I.; Ruani, G.; Ruben, M.; Cavallini, M. Multi-Modal Sensing in Spin Crossover Compounds. J. Mater. Chem. C $2015,3,7836-7844$. 
(23) Barrios, L. A.; Bartual-Murgui, C.; Peyrecave-Lleixa, E.; Le Guennic, B.; Teat, S. J.; Roubeau, O.; Aromí, G. Homoleptic Versus Heteroleptic Formation of Mononuclear Fe(II) Complexes with Tris- Imine Ligands. Inorg. Chem. 2016, 55, 4110-4116.

(24) Huang, W.; Shen, F.; Zhang, M.; Wu, D.; Pan, F.; Sato, O. Room-Temperature Switching of Magnetic Hysteresis by Reversible Single-Crystal-to-Single-Crystal Solvent Exchange in Imidazole- Inspired Fe(II) Complexes. Dalton Trans. 2016, 45, 14911-14918.

(25) Galet, A.; Munoz, M. C.; Real, J. A. Coordination Polymers Undergoing Spin Crossover and Reversible Ligand Exchange in the Solid. Chem. Commun. (Cambridge, U. K.) 2006, 4321-4323.

(26) Aromi, G.; Beavers, C.; Sanchez Costa, J.; Craig, G. A.; Minguez Espallargas, G.; Orera, A.; Roubeau, O. Snapshots of a Solid-State Transformation: Coexistence of Three Phases Trapped in One Crystal. Chemical Science 2016, 7, 2907.

(27) Miller, R. G.; Brooker, S. Reversible Quantitative Guest Sensing Via Spin Crossover of an Iron(II) Triazole. Chemical Science 2016, 7, 2501-2505.

(28) Pham, C. H.; Paesani, F. Spin Crossover in the $\{\mathrm{Fe}(\mathrm{pz})[\mathrm{Pt}-(\mathrm{CN}) 4]\}$ Metal-Organic Framework Upon Pyrazine Adsorption. J. Phys. Chem. Lett. 2016, 7, 4022-4026.

(29) Arcís-Castillo, Z.; Muñoz-Lara, F. J.; Muñoz, M. C.; Aravena, D.; Gaspar,A.B.;Sańchez-Royo,J.F.;Ruiz,E.;Ohba,M.;Matsuda,R.; Kitagawa, S.; et al. Reversible Chemisorption of Sulfur Dioxide in a Spin Crossover Porous Coordination Polymer. Inorg. Chem. 2013, 52, 12777-12783.

(30) Halder, G. J.; Kepert, C. J.; Moubaraki, B.; Murray, K. S.; Cashion, J. D. GuestDependent Spin Crossover in a Nanoporous Molecular Framework Material. Science 2002, 298, 1762-1765.

(31) Quesada, M.; de la Peña-O’Shea, V. A.; Aromí, G.; Geremia, S.; Massera, C.; Roubeau, O.; Gamez, P.; Reedijk, J. A Molecule-Based Nanoporous Material Showing Tuneable Spin-Crossover Behavior near Room Temperature. Adv. Mater. (Weinheim, Ger.) 2007, 19, 1397-1402.

(32) Southon, P. D.; Liu, L.; Fellows, E. A.; Price, D. J.; Halder, G. J.; Chapman,K.W.;Moubaraki,B.;Murray,K.S.;Letard,J.-F.;Kepert, C. J. Dynamic Interplay between Spin-Crossover and Host-Guest Function in a Nanoporous Metal-Organic Framework Material. J. Am. Chem. Soc. 2009, 131, 10998-11009.

(33) Lennartson, A.; Southon, P.; Sciortino, N. F.; Kepert, C. J.; Frandsen,C.;Mørup,S.;Piligkos,S.;McKenzie,C.J.ReversibleGuest Binding in a NonPorous Feii Coordination Polymer Host Toggles Spin Crossover. Chem. - Eur. J. 2015, $21,16066-16072$. 
(34) Coronado, E.; Minguez Espallargas, G. Dynamic Magnetic Mofs. Chem. Soc. Rev. 2013, 42, 1525-1539.

(35) Neville, S. M.; Halder, G. J.; Chapman, K. W.; Duriska, M. B.; Southon,P.D.;Cashion,J.D.;Letard,J.-F.;Moubaraki,B.;Murray,K. S.; Kepert， C. J. Single-Crystal to Single-Crystal Structural Trans- formation and Photomagnetic Properties of a Porous Iron(II) Spin- Crossover Framework. J. Am. Chem. Soc. 2008, 130, 2869-2876.

(36) Pham, C. H.; Cirera, J.; Paesani, F. Molecular Mechanisms of Spin Crossover in the $\{\mathrm{Fe}(\mathrm{pz})[\mathrm{Pt}(\mathrm{CN}) 4]\}$ Metal-Organic Framework Upon Water Adsorption. J. Am. Chem. Soc. 2016, 138, 6123-6126.

(37) Paulsen, H. Periodic Density Functional Calculations in Order to Assess the Cooperativity of the Spin Transition in Fe- (phen)2(NCS)2. Magnetochemistry 2016, 2, 14.

(38)Lemercier,G.;Brefuel,N.;Shova,S.;Wolny,J.A.;Dahan,F.; Verelst, M.; Paulsen, H.; Trautwein, A. X.; Tuchagues, J.-P. A Range of Spin-Crossover Temperature T1/2> 300 K Results from out-of- Sphere Anion Exchange in a Series of Ferrous Materials Based on the 4-(4-Imidazolylmethyl)-2-(2-Imidazolylmethyl)Imidazole (trim) Li- gand, [Fe(trim)2]X2 (X = F, Cl, Br, I): Comparison of Experimental Results with Those Derived from Density Functional Theory Calculations. Chem. - Eur. J. 2006, 12, 7421-7432.

(39) Bucko, T.; Hafner, J.; Lebegue, S.; Angyan, J. G. Spin Crossover Transition of Fe(phen)2(NCS)2: Periodic Dispersion-Corrected Density-Functional Study. Phys. Chem. Chem. Phys. 2012, 14, 5389- 5396.

(40) Bairagi, K.; Iasco, O.; Bellec, A.; Kartsev, A.; Li, D.; Lagoute, J.; Chacon, C.; Girard, Y.; Rousset, S.; Miserque, F.; et al. Molecular-Scale Dynamics of Light-Induced Spin Cross-over in a Two-Dimensional Layer. Nat. Commun. 2016, 7, 12212.

(41) Grimme, S. Semiempirical Gga-Type Density Functional Constructed with a LongRange Dispersion Correction. J. Comput. Chem. 2006, 27, 1787-1799.

(42) Himmetoglu, B.; Floris, A.; de Gironcoli, S.; Cococcioni, M. Hubbard-Corrected DFT Energy Functionals: The LDA+U Descrip- tion of Correlated Systems. Int. J. Quantum Chem. 2014, 114, 14-49.

(43) Di Valentin, C.; Pacchioni, G.; Selloni, A. Reduced and N-Type Doped TiO2: Nature of Ti3+ Species. J. Phys. Chem. C 2009, 113, 20543-20552.

(44) Bendavid, L. I.; Carter, E. A. CO2 Adsorption on Cu2O(111): A DFT+U and DFTD Study. J. Phys. Chem. C 2013, 117, 26048-26059. (45) Huang, M.; Fabris, S. Co Adsorption and Oxidation on Ceria Surfaces from DFT+U Calculations. J. Phys. Chem. C 2008, 112, 
8643-8648. (46)Capdevila-Cortada,M.;Łodziana,Z.;Loṕez,N.Performanceof

DFT + U Approaches in the Study of Catalytic Materials. ACS Catal. 2016, 6, 8370-8379.

(47) Grimme, S. Density Functional Theory with London Dispersion Corrections. Wiley Interdisciplinary Reviews: Computational Molecular Science 2011, 1, 211-228.

(48) Hasegawa, Y.; Takahashi, K.; Kume, S.; Nishihara, H. Complete Solid State Photoisomerization of Bis(Dipyrazolylstyrylpyridine)Iron- (II) to Change Magnetic Properties. Chem. Commun. (Cambridge, U. K.) 2011, 47, 6846-6848.

(49) Hasegawa, Y.; Sakamoto, R.; Takahashi, K.; Nishihara, H. Bis[(E)-2,6-Bis(1Hpyrazol-1-yl)-4-Styrylpyridine]Iron(II) Complex: Relationship between Thermal Spin Crossover and Crystal Solvent. Inorg. Chem. 2013, 52, 1658-1665.

(50) Brehm, G.; Reiher, M.; Schneider, S. Estimation of the Vibrational Contribution to the Entropy Change Associated with the Low- to High-Spin Transition in Fe(phen)2(NCS)2 Complexes: Results Obtained by Ir and Raman Spectroscopy and DFT Calculations. J. Phys. Chem. A 2002, 106, 12024-12034.

(51) Halcrow, M. A. Structure:Function Relationships in Molecular Spin-Crossover Complexes. Chem. Soc. Rev. 2011, 40, 4119-4142.

(52) Elhaik, J.; Kilner, C. A.; Halcrow, M. A. Structural Diversity in Iron(II) Complexes of 2,6-Di(pyrazol-1-yl)Pyridine and 2,6-Di(3- methylpyrazol-1-yl)Pyridine. Dalton Trans. 2006, 823-830.

(53) Fumanal, M.; Vela, S.; Novoa, J. J.; Ribas-Arino, J. Towards the Tailored Design of Benzotriazinyl-Based Organic Radicals Displaying a Spin Transition. Chem. Commun. (Cambridge, U. K.) 2015, 51, 15776- 15779.

(54) Vanderbilt, D. Soft Self-Consistent Pseudopotentials in a Generalized Eigenvalue Formalism. Phys. Rev. B: Condens. Matter Mater. Phys. 1990, 41, 7892-7895.

(55) Makov, G.; Payne, M. C. Periodic Boundary Conditions in Ab Initio Calculations. Phys. Rev. B: Condens. Matter Mater. Phys. 1995, 51, 4014-4022. 